\begin{tabular}{r|l} 
ARtigos & PESQUISA: \\
& $\begin{array}{r}\text { Compreensão da teoria do jornalismo } \\
\text { (contribuições colombianas) }\end{array}$ \\
$\begin{array}{r}\text { Copyright @ } 2013 \\
\text { SBPjor } / \text { Associação } \\
\text { Brasileira de } \\
\text { Pesquisadores em } \\
\text { Jornalismo }\end{array}$ & $\begin{array}{c}\text { RAUL HERNANDO OSÓRIO VARGAS } \\
\text { Universidade de Antioquia (Colômbia) }\end{array}$ \\
&
\end{tabular}

RESUMO - A história do jornalismo é um campo de contatos e empréstimos. Por esse motivo, a pesquisa em jornalismo tem e traz uma agenda ampla e complexa, como: o processo de produção jornalística, sua construção da linguagem por meio de diferentes formas, estruturas e tempos. A metodologia, epistemologia e pesquisa qualitativa em jornalismo; a história dos jornalistas e do jornalismo; ou seja, as relações múltiplas do jornalismo com a cultura, a memória, as teorias sociais e o discurso; campos que têm sido abordados e pesquisados na Ibero-América. Mas a pergunta sobre nosso Ethos profissional é o que continua a ser o eixo transversal da pesquisa, não diria apenas no continente americano, mas no mundo. Ela é fundamental em nossa existência e na análise profunda sobre esse conjunto de características e modos, de comportamentos, que compõem o caráter e a identidade da nossa profissão.

Palavras-chave: História e teoria do jornalismo. Epistemologia. Reportagem.

\title{
INVESTIGACIÓN: comprensión de la teoría del periodismo (contribuciones colombianas)
}

RESUMEN - La historia del periodismo es un espacio de contactos y préstamos. Por ese motivo, la investigación en periodismo tiene una agenda amplia y compleja que abarca, entre otros, temas como: el proceso de producción periodística y su construcción del lenguaje a través de diferentes formas, estructuras y tiempos; metodología, epistemología y la investigación cualitativa en periodismo; historia de los periodistas y del periodismo. Es decir, las relaciones múltiples del periodismo con la cultura, la memoria, las teorías sociales y el discurso, campos que han sido abordados e investigados en lberoamérica. Sin embargo, la pregunta sobre nuestro etos profesional continúa siendo el eje transversal de la investigación, no solo en el continente americano, sino en el mundo. Es fundamental en nuestra existencia y en el análisis profundo de ese conjunto de características y modos de comportamiento que componen el carácter y la identidad de nuestra profesión.

Palabras clave: Historia y teoría del periodismo. Epistemología. Reportaje.

\section{RESEARCH: understanding the theory of journalism (colombian contributions)}

\begin{abstract}
The history of journalism is a field of contacts and loans. For this reason, research in journalism has and brings a broad and complex agenda, including: the process of news production, its language construction through different forms, structures and tenses. The methodology, epistemology and qualitative research in journalism; the history of journalists and journalism; i.e., the multiple relationships between journalism and culture, memory, social theories and discourse; fields that have been studied and researched in Latin America. But the question on our professional Ethos is what remains the transverse axis of the research, not only in the American continent, but in the world. It is fundamental to our existence and to the depth analysis of this set of features and modes, behaviors, that make up the character and identity of our profession.

Keywords: History and theory of journalism. Epistemology. Report.
\end{abstract}


"O um é dois, sempre dois.

Unidade e dualidade são, como o espaço e o tempo, inseparáveis e diferentes.

O mesmo raciocínio é valido para o um e o outro, que não são variantes da dualidade original.

Do mesmo modo que o um está no dois,

o outro está no ser." 2

Octavio Paz

\section{APRESENTAÇÃO}

Pesquisar em suas diversas dimensões e profundidades o Ethos, tem sido o ponto de partida, que, como um fio condutor, permite-nos estudar a nossa personalidade histórica, muito vinculada à teoria da vida jornalística, da sua ética e estética, em suas diferentes fases, como fenômeno social, cultural, técnico, profissional e científico.

Lembremos que Ethos também é a raiz de ética. A ética, por sua vez, está intimamente ligada à estética, que reflete sobre as formas e os modos da narração dos acontecimentos. Tema que também tem ocupado os estudiosos do jornalismo na América Latina. Pensemos, por exemplo, nos estudos realizados sobre a obra jornalística de José Martí, em especial, o jornalismo que produziu a partir dos Estados Unidos, como correspondente, no período de 1880 a 1892, as chamadas Cenas Norte-americanas. Esses artigos de Martí constituem a mais penetrante análise feita por um escritor e pensador da língua espanhola.

Mas Martí deixou clara uma novíssima proposta: o artigo de jornal deve assumir a função pública do literário. Susana Rotker, jornalista e pesquisadora venezuelana, em sua pesquisa Fundação de uma escritura, prêmio Casa das Américas, em 1991, diz: "A transformação da escrita - e, portanto, dos modos de percepção da realidade - foi de tal importância que o jornalismo tornou-se, assim, o veículo dos primeiros textos verdadeiramente próprios na América Latina" (ROTKER, 1992, p. 9).

Na referida pesquisa, Susana Rotker, demonstra que mais da metade da obra escrita por José Martí e dois terços da produzida por Rubén Darío, compõem-se de textos jornalísticos. O crítico uruguaio Ángel Rama, na sua pesquisa Rubén Darío e o Modernismo, afirmou que 
"na procura do insólito, a renovação permanente, a ousadia temática, o registro das nuances, a mistura das sensações" (RAMA, 1970, p. 15) foram a essência das transformações sociais do fim do século XIX e da experiência jornalística interpretada como a incipiente profissionalização do escritor. O nascimento do jornalismo literário hispano-americano, ao cumprir-se nas mãos de intelectuais excepcionais, mostrou o caminho da dignificação da atividade jornalística.

O jornalismo como construção e prática social é o lugar, o âmbito intelectual, de onde se conforma sua teoria. É que em 1638 já se produzia um trabalho jornalístico na América Latina, fato confirmado pela pesquisa sobre Jornalismo narrativo na Colômbia (1638-2000), conduzida pelo pesquisador e jornalista Juan José Hoyos. Nesse trabalho, ele diz:

Em meio ao cheiro de poeira e umidade, na grande coleção de jornais e revistas colombianas dos séculos XIX e XX da Biblioteca da Universidade de Antioquia, e nos livros de seu Acervo Patrimonial, aprendi quase tudo o que sei do nosso passado e, portanto, do nosso presente. Também sobre a arte de contar. Estas são as minhas raízes. Ali nasceu este livro. Sua finalidade é fornecer aos leitores uma visão da história do jornalismo narrativo na Colômbia, dos autores que a construíram e da evolução do seu estilo (HOYOS, 2009, p. xxi).

Por sua parte, a pesquisadora Maryluz Mejía Vallejo, em seu trabalho Ferido a Chumbo, estuda o jornalismo na Colômbia (18801980). Nessa pesquisa constrói a história política e sociocultural do jornalismo escrito na Colômbia, e sua análise cruza as diversas vozes dos mesmos jornalistas, testemunhas da sua época.

\begin{abstract}
"Mas não são as empresas, com seus vaivéns, os protagonistas desta história, mas sim os jornalistas. Deles tomamos suas ideias sobre o jornalismo, produto da sua formação intelectual, ilustramos suas maneiras de escrever e de interpretar o país e seguimos a sua trajetória. Com as vozes dos colegas e contemporâneos, também reconstruímos seus perfis para exibi-los em sua grandeza e em sua pequenez, com seus acertos e suas contradições, especialmente quando fizeram parte do jogo de poderes. A partir daí, desmistificam-se algumas figuras sempre indiscutíveis e reverenciadas na historiografia; caem do céu alguns santos, beatos e canonizados. São esses retratos sem enfeites, nem adulações, muitas vezes irreverentes, que revelam a condição humana, essa que dá significado à obra jornalística tão próxima da literatura. $\mathrm{O}$ que demonstra até a saciedade é que o jornalismo na Colômbia, talvez mais do que em qualquer outro país da América Latina, está indissoluvelmente ligado à literatura" (VALLEJO, 2006, p. 12).
\end{abstract}

Por sua vez, Andrés Vergara Aguirre, em sua tese de doutorado História do subúrbio bogotano na imprensa, 1924-1946. Representações 
da cidade e suas infames nas crônicas de Ximénez e Osório Lizarazo3, conclui que os neofolhetinistas são uma categoria de repórteres que se utilizam das técnicas próprias do romance de folhetim, de algumas tendências do jornalismo sensacionalista e dos novos gêneros jornalísticos narrativos, o que lhes permitiu produzir relatos atraentes também aos novos leitores populares de uma Bogotá em processo de transição para a grande urbe, entre 1925 e 1945. Isso, associado ao processo de industrialização em que viveu a cidade, facilitou o crescimento acelerado do mercado de revistas e jornais em que os repórteres escreveram, entre eles Ximénez e Osório Lizarazo. "Por tudo isso, podemos afirmar que os neofolhetinistas estão no vértice dos processos de modernização e industrialização da imprensa bogotana"4 (VERGARA, 2012, p. 12).

Um dos grandes tesouros da sala de jornais da Universidade de Antioquia é a coleção do Mundo ao Dia, jornal que nasceu em 1924 e publicou boa parte do trabalho jornalístico do escritor José Antonio Osório Lizarazo5, que foi o repórter-estrela dessa publicação, em várias fases. Osório Lizarazo tem uma obra extensa, mas muitas de suas crônicas estão perdidas em antigos jornais, tornando difícil que as pessoas as leiam.

Andrés Molina, em sua pesquisa de mestrado sobre o jornalismo narrativo de Osório Lizarazo (PUERTA, 2009), recupera parte do trabalho jornalístico desse escritor, não incluído nos dois livros que reúnem seus textos: A cara da miséria (1926) e Romances e crônicas de J. A. Osório Lizarazo (1978).

Em sua pesquisa, Puerta Molina revela o trabalho de jornalismo narrativo de um dos melhores expoentes que a Colômbia já teve. Para alcançar esse objetivo, fez um rastreamento em jornais, transcreveu e reproduziu textos, para que os leitores e pesquisadores em jornalismo tenham acesso a esses escritos que a dissertação analisa.

Francisco de Paula Muñoz (natural de Medellín, 1840-1914) é um dos jornalistas e escritores mais importantes da Antioquia durante a segunda metade do século XIX e primeira década do século XX. Ao mesmo tempo, é um dos autores mais desconhecidos, não só para as novas gerações de jornalistas, mas também para os historiadores e pesquisadores que estudam o jornalismo. Em 1874, Muñoz dedicou-se por mais de um ano a pesquisar - como jornalista - um crime que tinha comovido a cidade de Medellín. E escreveu uma narrativa de 260 páginas "ao mesmo tempo em que os acontecimentos se desenrolavam, e com toda a escrupulosa imparcialidade" (HOYOS, 2002, p. 11) que era capaz, em tempos em que ainda se ignorava o desenlace da história. 
Assim que se fez a captura e o julgamento dos responsáveis, Muñoz publicou a história completa dos fatos em um livro intitulado: O crime de abacatal. A obra começou a ser preparada na imprensa do Estado de Antioquia, ainda em 1874, mas veio a público somente no ano seguinte, depois de finalizado o julgamento de Daniel Escovar e dos outros acusados de tomarem parte no crime.

O livro de Francisco de Paula Muñoz é uma amostra pioneira e singular da reportagem na Colômbia, em uma época na qual nem sequer se usava essa palavra nos jornais. Lembremos que o termo reportagem, de acordo com Hobsbawm, é registrado pela primeira vez nos dicionários franceses, em 1929. E, pelos ingleses, em 1931: "se atribui ao jornalista comunista tcheco Erwin Kisch ter colocado em moda o termo na Europa central, na década de 1920" (HOBSBAWM, 1995, p. 195).

Muñoz converteu-se em um dos precursores da reportagem na Colômbia. Um pioneiro da reportagem (HOYOS, 2002) é uma pesquisa que estuda o livro desse jornalista, no qual se empregaram muitas das técnicas e métodos que, muitos anos depois, ao longo do século XX, foram utilizados na reportagem moderna.

Em 1957, na Argentina, o jornalista Rodolfo Walsh publica Operação Massacre, que consiste em uma reportagem que teve um desenvolvimento tão expressivo, a ponto de ser considerado o primeiro livro-reportagem moderno. Sobre esse autor, mais conhecido internacionalmente, existem várias pesquisas desde a perspectiva da teoria do jornalismo e até a da narrativa contemporânea latino-americana.

E se olharmos um pouco na história, em um sentido panorâmico, só como exemplo, podemos encontrar o seguinte: Desde os séculos XIII e XIV até nossos dias, são preservadas as referências explícitas de todos os produtos de informação produzidos pelo jornalismo. Além disso, há uma continuidade lógica na atividade jornalística e uma evolução controlável e inteligível. Mas o jornalista é fundamentalmente o Ser Humano da Renascença, quando aparecem as gazetas italianas, entre os séculos XIV e XVI.

Há ainda registros que mostram que um dos primeiros jornais surgidos na América Latina foi a Folha do México, publicada em 1541, na qual se narravam os acontecimentos que tiveram lugar durante o terremoto da Guatemala. No século XVII, proliferam no nosso continente, especialmente no México e em Lima, folhas que se publicavam com as notícias da época. Um século mais tarde, estabelecem-se jornais contínuos e com seções diferentes. A Gazeta do México é de 1722. Em 1729, na Guatemala, aparece a Gazeta da Guatemala e, na Costa Rica, a 
Gazeta Mensal. No Peru, aparecem A Gazeta de Lima em 1743 e o Diário de Lima em 1790.

Nesse sentido, a lista continua e vão aparecendo mais países e crescendo o número de jornais, que são o registro da vida do jornalismo. Comparar seu estudo e análise com outras fontes e outros pontos de vista nos permite ver a dimensão da personalidade histórica dos jornalistas da época e suas variadas problemáticas. O jornalismo, como objeto de estudo, bem como a importância da reflexão teórica sobre o seu processo histórico nos levam a conhecer os espaços e tempos dos jornalistas das diferentes épocas, a fim de valorizar adequadamente o presente. Tratase, então, de ampliar o alcance dos estudos do jornalismo, dotando-os de "um sentido de memória sobre os meios e seus manejos históricos, assim como sobre a evolução do mundo do jornalismo (LOPEZ, 2005, p. 15)".

Mas é um mundo pensando no outro. Sob essa ótica, Juan José Garcia (1997, p. 182) - em sua pesquisa sobre A Dimensão Hermenêutica do Jornalismo, resultado das consultas e das observações prévias e de seu confronto permanente com a realidade do jornalismo colombiano questiona

\begin{abstract}
Pode-se afirmar, sem qualquer dúvida, que seja tão humano o jornalismo como se costuma crer, se a relação que estabelece não está fundamentalmente no compromisso com a solidariedade humana, no respeito pela dignidade da pessoa e no trabalho consequente pela concreção dos direitos fundamentais? Como superar o velho e equivocado critério de considerar o outro como objeto, como instrumento, como dado estatístico e muitas vezes como ninguém?
\end{abstract}

E ele mesmo responde:

\begin{abstract}
Nós é uma das palavras-chave da nossa atormentada situação histórica. O outro se fez realidade inevitável, e todos adquirimos viva consciência disto. Eis aqui uma clara e conclusiva resposta à pergunta inicial sobre a quem serve o jornalismo e por que é importante procurar o sentido, no desenvolvimento da abordagem hermenêutica (GARCIA, 1997, p. 18 - grifos do autor).
\end{abstract}

Essas reflexões sobre o jornalismo, sua prática e teoria, permitem-nos ver as diversas dimensões da pesquisa na área, as suas representações, o contexto em que foram produzidas com uma visão ampla e interdisciplinar e a partir de uma perspectiva da história cultural e intelectual do jornalismo.

Nessa perspectiva, imagine se fossem realizadas pesquisas em toda América Latina, como essa feita por Juan José Hoyos 
sobre o jornalismo narrativo na Colômbia. O que acharíamos? Acredito que a teoria do jornalismo que emergiria desse iceberg seria muito valiosa para a história e para a epistemologia do jornalismo. Talvez, parte dessa pesquisa já esteja sendo realizada e a desconhecemos.

Esses são alguns exemplos de como o jornalismo, sua construção da realidade e sua reflexão teórica se tem apresentado na América Hispânica. Se levantarmos os pesquisadores em jornalismo de cada um dos países do continente, descobriremos que em nossas nações houve e há muito pioneirismo. E que tem sido feita e se faz pesquisa séria e consistente, que contribui com a conformação da epistemologia do jornalismo. Mas, infelizmente, não nos integramos, não nos conhecemos. Se nos perguntam na América Latina por Truman Capote ou Otto Groth, com segurança até os alunos mais jovens sabem quem são. Entretanto, se perguntamos a esses mesmos estudantes de jornalismo hispanoamericanos se sabem quem é Adelmo Genro Filho, poucos saberão.

Não concordo com o que dizem alguns autores, que a cada dia se fazem menos pesquisas em jornalismo. Sem dúvida, hoje se fazem muito mais, com maior profundidade, profissionalismo intelectual e científico. O que precisamos é uma rede de pesquisadores da América Latina para ajudar a descobrir, organizar e sistematizar o que foi feito até agora.

Como disse o escritor Carlos Fuentes (2006, p. 1): "Temos a grande sorte de que a personalidade ibero-americana é indígena, africana, mulata, mestiça e, através da Península Ibérica, mediterrânea, grega, latina, árabe, judia, cristã e laica. Nós somos, podemos ser, também o microcosmos da convivência". Por conseguinte, devemos ter a capacidade de incorporar essa riqueza na ação político-social, no mundo educacional e no cotidiano de todos os países ibero-americanos; fundamentalmente na prática do jornalismo e na sua reflexão teórica, daquilo que Fuentes (1990) chamou de realidade sociocultural da Indo-Afro-Ibero-América.

Ademais, torna-se também importante dar um passo à frente e estudar a teoria do jornalismo como crítica cultural, uma vez que o jornalismo é um habitat de diversidade e complexidade, que se move e vive no tecido social das nossas realidades. O jornalismo como termo, conceito, noção, história, profissão e investigação vem se impondo na sociedade contemporânea; não sendo um conceito fechado. Pelo contrário, é uma noção aberta, complexa, multidisciplinar, que se interessa pelos acontecimentos e suas conexões. É o caminho da pluralidade, com seus métodos e pesquisas sobre os sentidos humanos. 


\section{JORNALISMO E SEUS SENTIDOS DAS REALIDADES}

$O$ que interessa aos jornalistas tem a ver com as necessidades do continente?

Nesse caso, penso que devem ser criadas Agendas de Continente, que puxem os temas dos estudos e pesquisas do jornalismo para os problemas vivos da América Latina. E isso está ligado a temas importantes, quais sejam: o papel dos jornalistas frente às violências; os desafios das culturas digitais; e como os jornalistas estão se apropriando, ou não, dessas novas narrativas.

O setor que parece mais impactado com essa mudança de entorno é o educativo. E aqui jornalismo e educação formam um casal indispensável para educar as pessoas para pensarem e se tornarem cidadãs. Desse modo, o jornalismo cumpre um papel essencial ao construir com sua narrativa dos acontecimentos o exercício da cidadania; estando, assim, vinculado aos novos movimentos sociais, que estão transformando desde baixo a vida das pessoas e a forma de fazer política. O que significa também uma forma nova de fazer e pesquisar no jornalismo. É, portanto, um grande desafio.

Em nosso campo, temos de começar a nos reconhecer, porque não há uma só maneira de ser jornalista. Sem uma agenda, como percorrer a pesquisa do jornalismo? Os exemplos que coloquei são mínimos em comparação com a quantidade de pesquisas realizadas em nossa área. A partir dessa babel de pesquisas, devemos compor uma lista inicial que seja desenvolvida por todos os participantes dessa rede, o que inclui a possibilidade de criar um site na internet para socializar esses conhecimentos e dar maior visibilidade à nossa área.

Essa lista inicial seria como um guia para se ter mais elementos a respeito de onde estamos e o que fazemos, bem como norteie por onde ir e com que horizontes. Esse guia permitirá nos encontrarmos, realizar balanços, diagnósticos e propor ações, pois o jornalismo e o jornalista continuam sendo fundamentais para a democracia no mundo contemporâneo, na Era dos Líquidos.

Nessa perspectiva, Zigmund Bauman, em seu livro Modernidade Líquida disse:

\footnotetext{
Em seu estágio pesado, o capital estava tão fixado ao solo quanto os trabalhadores que empregava. Hoje o capital viaja leve apenas com a bagagem de mão, que inclui nada mais que pasta, telefone celular e computador portátil. Pode saltar em qualquer ponto do caminho, e não precisa demorar-se em nenhum lugar além do tempo que durar sua satisfação. O trabalho, porém, permanece tão imobilizado quanto no passado -, mas o lugar em que ele imaginava estar fixado de uma vez por todas perdeu sua solidez de outrora; buscando rochas, as âncoras encontram areias
} 
movediças. Alguns dos habitantes do mundo estão em movimento; para os demais, é o mundo que se recusa a ficar parado (BAUMAN, 2001, 70-71).

Agora tudo muda com uma velocidade maior nesse processo de fazer jornalismo e de educar os jornalistas. O que saber? O que aprender? O que ensinar? O que fazer? Como comprometer-se? Seriam os temas para um Congresso Internacional de Educação e Ensino do Jornalismo.

Como disse Edgar Morin na sua proposta A cabeça bem-feita: "a educação pode ajudar a nos tornarmos melhores, se não mais felizes, e nos ensinar a assumir a parte prosaica e viver a parte poética de nossas vidas" (MORIN, 2001, p. 11).

Devemos, portanto, deixar de pensar só nas fronteiras e construir as relações e os entrelaçamentos que dignificam o jornalismo e seus caminhos (métodos) de pesquisa nos labirintos globais, a fim de projetar as mudanças na cultura híbrida de que fala Néstor García Canclini (1990).

\section{NOTAS}

1. Este trabalho forma parte do projeto de pesquisa: Jornalismo e reportagem transcultural, desenvolvido na Universidade de Antioquia - Colômbia, Sistema Universitário de Pesquisa - CODI No 584 , e foi apresentado no $10^{\circ}$ Encontro Nacional de Pesquisadores em Jornalismo, Curitiba, 9 de novembro de 2012.

2. PAZ, Octavio. Nosotros: los otros. Prólogo al tomo 10 de las Obras Completas: Ideas y costumbres, II, Usos y símbolos.

3. José Joaquín Jiménez (Bogotá, 1916-1946) foi um dos repórteres mais populares de Bogotá naquela época; aqui é chamado pelo pseudônimo que mais utilizou, Ximénez. José Antonio Osorio Lizarazo (Bogotá, 19001964), que depois seria um prolífico romancista, foi outro dos repórteres mais reconhecidos nos anos 1920 em Bogotá.

4. Memorias Primer Congreso de Historia Intelectual de América Latina, Medellín, 12-14 de septiembre de 2012. Mesa: Historia del periodismo y la opinión pública en América Latina.

5. El trabajo periodístico de Osorio Lizarazo fue muy amplio: redactor de $\mathrm{El}$ Sol, Bogotá 1922; redactor en Gil Blas, Bogotá 1923-1924; reportero de Mundo al Día, Bogotá 1924-1929; corresponsal en Centro de América de 
Cromos, Bogotá 1929; redactor de viaje de El Espectador, Bogotá 1929; redactor (1929-1931) de La Prensa, Barranquilla; fundador y jefe de redacción (1933-1934) de El Heraldo, Barranquilla; director de El Diario Nacional, Bogotá 1935-1936; colaborador de la revista Pan, Bogotá 1937-1939; corresponsal de viaje (1939), redactor (1934-1935, 19391940), colaborador (1941-1946) y corresponsal en Argentina (19461950) de el periódico El Tiempo de Bogotá; colaborador de la Revista de la Indias, Bogotá 1942-1946, 1954; colaborador de la Revista de América (El Tiempo), Bogotá 1945-1950; fundador y director del periódico Jornada - por la restauración mora de la República, Bogotá 1944-1945; jefe de redacción de Sábado - Semanario al servicio de la cultura y de democracia en América, Bogotá 1945; colaborador de la revista Economía Colombiana, Bogotá 1955; colaborador de Dinámica Social, Buenos Aires 1950-1956 (Revista del Centro de Estudios Económico Sociales), director de El Caribe, Ciudad Trujillo-República Dominicana 1958-1960.

\section{REFERÊNCIAS}

BAUMAN, Zigmunt. Modernidade líquida. Rio de Janeiro: Zahar, 2001.

FUENTES, Carlos. Valiente mundo nuevo: Épica, utopía y mito en la novela hispanoamericana. México: Fondo de Cultura Económica, 1990.

FUENTES, Carlos. No hay discurso sin nuestra voz. VII Foro Iberoamérica. Ciudad de México: 30 Noviembre de 2006. Discurso.

GARCÍA CANCLINI, Néstor. Culturas híbridas: estrategias para entrar y salir de la modernidad. Buenos Aires: Paidós, 2008.

GARCÍA, Posada Juan José. La dimensión hermenéutica del periodismo. Medellín: Editorial Universidad Pontificia Bolivariana, 1997.

HOBSBAWM, Eric John Ernest. Historia del siglo XX. Barcelona: Crítica, 1995.

HOYOS, Naranjo Juan José. La pasión de contar. El periodismo narrativo en Colombia. 1638-2000. Medellín: Hombre Nuevo Editores-Editorial Universidad de Antioquia, 2009.

HOYOS, Naranjo Juan José. Un pionero del reportaje: Francisco de Paula Muñoz y El crimen de Aguacatal. Medellín: Hombre Nuevo Editores-Editorial Universidad de Antioquia, 2002. (Colección de Periodismo)

LÓPEZ, Fabio. Presentación del Dossier sobre historia de los medios de comunicación social y del periodismo en Colombia. Revista Historia Crítica, Bogotá, Universidad de los Andes, n. 28, 2005.

MARTÍ, José. "Escenas norteamericanas". In: Obras Completas. La Habana: Editorial Ciencias Sociales, 1986. Tomos 9-12.

MORIN, Edgar. A cabeça bem-feita: repensar a reforma, reformar o 
pensamento. Rio de Janeiro: Bertrand Brasil, 2001.

PUERTA, Molina Andrés Alexander. Una recuperación del olvido para el escritor de los olvidados: Periodismo narrativo de José Antonio Osorio Lizarazo. Disertación de Maestría. Medellín: Universidad de Antioquia, Facultad de Comunicaciones, 2009.

RAMA, Ángel. Rubén Darío y el modernismo. Caracas: Universidad Central de Venezuela, 1970.

ROTKER, Susana. Fundación de una escritura: Las crónicas de José Martí. La Habana: Ediciones Casa de las Américas, 1992.

VALLEJO, Mejía Maryluz. A Plomo Herido: Una crónica del periodismo en Colombia (1880-1980). Bogotá: Editorial Planeta, 2006.

WALSH, RodolfoJ. Operación Masacre: un proceso que no ha sido clausurado. Buenos Aires: Colección Documentos, Ediciones Sigla, 1957.

\begin{abstract}
Raúl Hernando Osorio Vargas é Mestre e Doutor em Comunicação, na área do Jornalismo pela Escola de Comunicações e Artes da Universidade de São Paulo. Professor Assistente do Programa de Jornalismo da Faculdade de Comunicações da Universidade de Antioquia - Colômbia. Membro do Grupo de Estudos Literários, GEL, classificação A, de COLCIENCIAS.E-mail:osoriova@gmail.com
\end{abstract}




\section{PESQUISA: COMPREENSÃO DA TEORIA DO JORNALISMO}

